\title{
MENELAAH KEMBALI GAGASAN PEMIKIRAN DAN PERJUANGAN AHMAD SYAFII MAARIF JALAN TENGAH KEBERAGAMAN
}

\author{
Wandi \\ STIE Syari'ah Al-Mujaddid, Jambi \\ huseinwandi220@gmail.com \\ M. Arif Musthofa \\ STIE Syari'ah Al-Mujaddid, Jambi \\ 7ariefherio@gmail.com \\ Khusnul Yatima \\ STIE Syari'ah Al-Mujaddid, Jambi \\ yatimakhusnul@yahoo.co.id
}

\begin{abstract}
This research was specifically written as a result of reflection on diversity in Indonesia at this time, where friction in the name of ethnicity, race, religion and even the issue of state always appear in the public sphere, departing from the problem above, the author wants to "re-examine ideas, thoughts and Ahmad SyafiiMaarif's struggle for a middle path of diversity" a search for solutions to the problemsas the writer has mentionedabove. This type of research was a literature study by collecting primary books about the works and thoughts of Ahmad SyafiiMaarif both written by himself and written by others. The result was an important key to realizing a glorious Islamic civilization in Indonesia. Integration between Islam, Indonesia and humanity is urgently needed where these three issues must be resolved in order to stem the friction, for the achievement of a friendly Islam, providing security, security and protection of the inhabitants of the archipelago in a humanitarian frame.
\end{abstract}

Keywords: Ideas, Thoughts, Diversity

\begin{abstract}
ABSTRAK
Kajian ini secara khusus ditulis sebagai hasil refleksi tentang keberagaman di Indonesia pada saat ini, dimana gesekan-gesekan atas nama suku, ras, agama bahkan persoalan bentuk negara selalu saja muncul di ruang publik, berangkat dari masalah diatas penulis ingin "menelaah kembali gagasan, pemikiran dan perjuangan Ahmad Syafii Maarif jalan tengah keberagaman" sebagai pencarian solusi atas masalah diatas. Jenis penelitian pada studi adalah studi pustaka dengan mengumpulkan buku-buku primer tentang karya dan pemikiran Ahmad Syafii Maarif baik yang ditulisnya sendiri maupun yang ditulis orang lain. Hasilnya adalah kunci penting untuk mewujudkan
\end{abstract}


peradaban Islam yang gemilang di Indonesia sangat dibutuhkan integrasi antara Islam, keIndonesiaan dan kemanusiaan dimana tiga persoalan ini harus selesai agar dapat membendung gesekan-gesekan seperti yang penulis sebutkan diatas, demi tercapainya Islam yang bersahabat, memberi keadialan, keamanan dan perlindungan kepada penduduk nusantara dalam bingkai kemanusiaan.

\section{Kata Kunci: Gagasan, Pemikiran, Keberagaman}

\section{A. PENDAHULAN}

Di era perkembangan teknologi informasi, bangsa Indonesia tengah diterpa berbagai macam permasalahan khususnya persoalan tentang titik terang posisi agama Negara dan sistem demokrasi yang seakan-akan tidak pernah selesai. Namun ditengah berbagai persoalan itu bangsa Indonesia tidak akan pernah pula habis bermunculan tokoh-tokoh pemikir, yang selalu memikirkan bagaimana nasib bangsa ini ke depan salah satunya adalah tokoh sekaligus cendikiawan berasal dari tanah minang yaitu Ahmad Syafii Maarif.

Jika berbicara tentang tokoh pemikir Islam tentu pemikiran Ahmadi Syafii Maarif tidak bisa dikesampingkan, apalagi jika ditelaah beberapa dekade terakhir, saat bermunculannya isu politisasi agama. Ahmad Syafii Maarif sering kali dimintai pendapatnya tentang hal tersebut bahkan kerap kali ia sering kali dimintai pendapatnya oleh presiden tentang pendapatnya tersebut. Hal ini dikarenakan selain pemikiranya sudah diakui, tentu konsep-konsepnya yang brilian tentang pemikiran Islam Indonesia sudah diakui sejak dahulu oleh sosok yang sudah dikenal luas sebagai cendikiawan muslin dan juga guru ini.

Gagasan dan refleksi pemikirannya lahir dari keprihatinan akan kondisi umat Islam yang merupakan penduduk mayoritas di bumi nusantara, sudah semestinya tidak lagi mempesoalkan antara hubungan Islam, keIndonesiaan dan kemanusiaan. Menurutnya ketiga konsepsi tersebut haruslah senafas agar Islam yang berkembang di Indonesia adalah sebuah Islam yang ramah dan terbuka. ${ }^{1}$

Inilah tantangan sekaligus yang akan digarap dan dikampanyekan oleh Ahmad Syafii Maarif. Menurutnya, jika keIslaman, keIndonesiaan, dan kemanusiaan telah senafas dalam jiwa, fikiran, dan tindakan umat Islam Indonesia maka umat akan mampu

\footnotetext{
${ }^{1}$ Ahmad Syafii Maarif, Islam dalam Bingkai Keindonesiaan dan Kemanusiaan: Sebuah Refleksi Sejarah (Bandung: Mizan Pustaka), hlm 410.
} 
memberi solusi terhadap masalah-masalah besar bangsa. Sebuah Islam yang dinamis, dan bersahabat, yang memberi keadilan, keamanan, dan perlindungan kepada penduduk nusantara. Sebuah Islam yang sepenuhnya berpihak kepada rakyat miskin, dan menolok kemisikinan sehingga berhasil dihalau dari Negara Kesatuan Republik Indonesia.

Tentu jika flashback ke belakang masih banyak pekerjaan-pekerjaan besar yang harus dibenahi oleh segenap pemerintah dan masyarakat Indonesia, terutama masalahmasalah keIndonesiaan dan kemanusiaan. Berangkat dari uraian tersebut tidak ada salahnya jika kita menelaah kembali pemikiran-pemikiran cemerlang dari sang guru bangsa Ahmad Syafii Maarif mengenai. Hubungan Islam dan Negara Indenesia, Pemikiran Islam Ahmad Syafii Maarif dalam Bingkai KeIndonesiaan dan Kemanusiaan, Toleransi Beragama Ahmad Syafii Maarif, serta gagasan Tentang Relasi Negara dan Agama yang digagasnya. Dari penelitian ini diharapkan dapat ditemui benang merah akar permasalahan keIndonesiaan dan Kemanusiaan yang sedang menerpa umat Islam Indonesia saat ini.

\section{B. METODE PENELITIAN}

Kajian ini berdasarkan studi literatur dan interpretasi secara mendalam serta akumulasi pemahaman dari berbagai sumber buku-buku primer terpercaya yang menulis tentang pemikiran Ahmad Syafii Maarif. Studi literatur berasal dari hasil penelitian terdahulu, dan buku-buku terpercaya dan telah dijadikan sebagai acuan utama untuk memahami konsep tentang Meleaah Kembali Gagasan, Pemikiran dan Perjuangan Ahmad Syafii Maarif Jalan Tengah Keberagaman. Pengumpulan data dilakukan melalui metode tinjauan pustaka terhadap buku-buku karangan tentang pemikiran Ahmad Syafii Maarif.

\section{HASIL DAN PEMBAHASAN}

\section{Biografi}

Ahmad Syafii Maarif lahir di Nagari Calau, Sumpur Kudus, Minangkabau 31 Mei 1935 atau sekitar 84 tahun yang lalu. Ia lahir dari pasangan Ma'rifat Rauf Datuk Rajo Melayu, dan Fathiyah. Ayahnya adalah seorang saudagar gambir, yang belakangan diangkat sebagai kepala suku di kaumnya. Sewaktu Ahmad Syafii Maarif berusia satu 
setengah tahun, ibunya meninggal, Maarifpun kemudian dititipkan ke rumah adik ayahnya yang bernama Bainah.

Pada tahun 1942, ia masuk sekolah rakyat setingkat SD di Simpur Kudus, Ahmad Syafii Maarif juga belajar agama disebuah Madrasah Ibtidaiyah Muhammadiyah pada sore hari dan malamnya belajar mengaji di surau yang berada di sekitar tempat ia tinggal, sebagaimana umumnya anak laki-laki di Minangkabau pada masa itu.

Pendidikannya di Sekolah Rakyat, yang seharusnya ia tempuh selama enam tahun, dapat ia selesaikan selama lima tahun. Ia tamat dari SR pada tahun 1947, tetapi tidak memperoleh ijazah karena pada masa itu terjadi perang revolusi kemerdekaan. Namun, setelah tamat, karena beban ekonomi yang di tanggung ayahnya, ia tidak dapat meneruskan sekolahnya selama beberapa tahun. Baru pada tahun 1950, ia masuk ke Madrasah Muallimin Muhammadiyah di Balai Tengah, sampai duduk di bangku kelas tiga.

\section{a. Merantau ke Jawa}

Pada tahun 1953, dalam usia 18 tahun, ia meninggalkan kampung halamannya untuk merantau ke pulau Jawa. Bersama dua adik sepupunya, yakni Azra'I dan Suward, ia diajak belajar ke Yogyakarta oleh Muhammad Sanusi Latif, namun sesampainya di Yogyakarta, niatnya semula untuk meneruskan sekolahnya ke Madrasah Muallimin di kota itu tidak terwujud, karena pihak sekolah menolah menerimanya di kelas empat dengan alasan kelas sudah penuh. Tidak lama setelah itu, ia justru diangkat menjadi guru bahasa Inggris dan bahasa Indonesia di sekolah tersebut tapi tidak lama.

Pada saat bersamaan, ia bersama Azra'i mengkuti sekolah montir sampai akhirnya lulus setelah beberapa bulan belajar. Setelah itu, ia kembali mendaftar ke Muallimin dan akhirnya ia diterima tetapi ia harus mengulang kuartal terakhir kelas tiga. Selama belajar di sekolah tersebut, ia akfit dalam organisasi kepanduan Hizbul Wathan dan pernah menjadi pemimpin redaksi majalah Sinar (kin dibawahi oleh lembaga pers Muallimin), sebuah majalah pelajar Mualimmin di Yogyakarta.

Setelah ayahnya meninggal pada 5 Oktober 1955, kemudian ia tamat dari Muallimin pada 12 Juli 1956, ia memutuskan untuk tidak melanjutkan sekolahnya, terutama karena masalah biaya. Dalam usia 21 tahun, tidak lama setelah tamat, ia berangkat ke Lombok untuk menjadi guru. Sesampai di Lombok Timur, ia disambut 
oleh pengurus Muhammadiyah setempat, lalu menuju sebuah kampung di Pohgading tempat ia ditugaskan sebagai guru.

Setelah setahun lamanya mengajar di sebuah sekolah Muhammadiyah di Pohgading, sekitar bulan Maret 1957, dalam usia 22 tahun, ia mengunjungi kampung halamannya, kemudian kembali lagi ke pulau Jawa untuk melanjutkan pendidikan ke perguruan tinggi di Surakarta. Sesampai di Surakarta, ia masuk ke Universitas Cokroaminoto dan memperoleh gelar sarjana muda pada tahun 1964. Setelah itu, ia melanjutkan pendidikannya untuk tingkat doctoral pada Fakultas Keguruan Ilmu Sosial, IKIP (sekarang Universitas Negeri Yogyakarta) dan tamat pada tahun 1968.

\section{b. Karir}

Selanjutnya bekas aktivis Himpunan Mahasiswa Islam ini, terus menekuni ilmu sejarah dengan mengikuti program master di Departemen Sejarah Universitas Ohio, AS. Sementara gelar doktornya diperoleh dari Program Studi Bahasa dan Peradaban Timur, Universitas Chicago AS, dengan disertasi: Islam as the Basis of State: A Study of the Islamic Political Ideas as Reflected in the Consistent Assembly Debates in Indonesia.

Selama di Chicago inilah, anak bungsu dari empat bersaudara ini, terlibat secara intensif melakukan pengkajian terhadapa al-qur'an, dengan bimbingan dari seorang tokoh pembaharu pemikiran Islam, Fazlur Rahman. Di sana pula, ia kerap terlibat diskusi intensif dengan Nurcholish Madjid dan Amien Rais yang mengikuti pendidikan doktornya.

\section{c. Aktivitas}

Setelah meninggalkan posisinya sebagai ketua umum PP Muhammadiyah, kini ia aktif dalam komunitas Maarif Institute, disamping itu guru besar IKIP Yogyakarta ini, juga rajin menulis, disamping itu ia juga menjadi pembicara dalam sejumlah seminar. Sebagian besar tulisannya adalah masalah-masalah seputaran Islam dan dipublikasikan di sejumlah media cetak. Selain itu ia juga menulis berbagai macam buku seputaran Islam. Berangkat dari buku-buku karya Ahmad Syafii Maarif, penulis mencoba memetakan beberapa pemikiran progresif tentang Islam menurut Ahmad Syafii Maarif. 


\section{Telaah Hubungan Islam dan Negara Indonesia}

Dalam kesempatan ini, penulis akan memetakan pandangan Ahmad Syafii Maarif tentang hubungan Islam dan Negara. Diskusi mengenai tema ini mencakup dua aspek, yaitu aspek normative dan aspek historis. Dengan mendiskusikannya, diharapkkan dapat memperjelas bagaimana sesungguhnya relasi Islam dan Negara.

Menurut Ahamd Syafii Maarif, secara dokrinal, Islam tidak menetapkan dan menegaskan pola apapun tentang teori Negara Islam yang wajib digunakan oleh kaum muslim. H.A.R Gibb seperti dikutip Buya Ahmad Syafii Maarif, memaparkan bahwa baik Al-qur'an maupun sunah tidak memberikan petunjuk yang tegas tentang bentuk pemerintahan dan lembaga-lembaga politik lainnya sebagai cara bagi umat mempertahankan persatuannya. ${ }^{2}$

Terminologi "kerajaan Islam", "kesultanan Islam" atau "monarki Islam" menurut Ahmad Syafii Maarif sebenarnya bersifat kontradiktif di dalamnya. Monarki, kesultanan, dan seterusnya tidak secara otomatis dapat menjadi Islam kendatipun mengunakan embel-embel nama Islam, ia juga mengkritik gagasan tentang Negara Islam. Menurutnya gagasan Negara Islam tidak memiliki basis religio intlektual yang kukuh, yang berbicara secara teoritik.

Terminologi Negara Islam tidak ada dalam kepustakaan Islam klasik. Dalam piagam madina pun, terminologi ini tidak ditemukan. Gagasan Negara Islam (DaulatulIslamiyyah), menurutnya, merupakan fenomena abad 20. Kendati demikian, Islam sangat membutuhkan mesin Negara untuk membumikan cita-cita dan ajaran-ajaran moral. $^{3}$ Al-Qur'an yang penuh dengan ajaran imperatif moral, lanjutnya tidak dapat diragukan lagi sangat membutuhkan Negara sebagai institusi "pemaksa" bagi pelaksanaan perintah dan ajaran moralnya. ${ }^{4}$

Argumentasi Ahmad Syafii Maarif ini berangkat dari asumsi bahwa Islam bukanlah sekedar cita-cita moral dan nasihat-nasihat agama yang lepas begitu saja. Islam membutuhkan sarana sejarah untuk mewujudkan cita-cita moralnya yang mencakup seluruh aspek kehidupan. Sarana yang dimaksud Ahmad Syafii Maarif tidak

\footnotetext{
${ }^{2}$ Ahmad Syafii Maarif, Islam dan Masalah Kenegaraan: Studi tentang Percaturan dalam Konstituante, (Jakarta: LP3ES, 1985), hlm 10.

${ }^{3}$ Ahmad Syafii Maarif, Islam: Kekuatan Doktrin dan Keagamaan Umat, (Yogyakarta: Pustaka Pelajar, 1997), hlm 60-62.

${ }^{4}$ Ahmad Syafii Maarif, Islam dan Politik: Teori Belah Bambu Masa Demokrasi Terpimpin 19591965, (Jakarta: Gema Insani Press, 1996), hlm 193.
} 
lain adalah Negara. Oleh karenanya, ia menolak pandangan yang menghendaki pemisahan Islam dan Negara. Menurutnya, disamping tidak memilki basis teoritis yang kuat, pendapat seperti itu dalam waktu yang panjang akan berakhir menjadi kerja bunuh diri.

Ahmad Syafii Maarif menganggap bahwa semua aspek kehidupan tidak dapat ditempatkan dalam kategori yang dikotomis, antara ibadah dan kerja sekuler. ${ }^{5}$ Dalam hal ini, ia sepakat dengan pandangan Ibnu Taimiyah dalam kitab as-siyasi as-syar'iyah yang mengemukakan bahwa Negara (kekuasaan politik) merupakan sesuatu yang penting bagi agama. Tanpa adanya Negara, agama tidak akan tegak dan kukuh. Ibnu Taimiyah menuturkan bahwa Allah mewajibkan amar ma'ruf nahi mungkar, jihad, keadilan, dan semua hal yang diwajibkan oleh Allah. Hal ini tidak mungkin terealisasi dengan sempurna tanpa kekuatan dan kekuasaan. ${ }^{6}$

Menariknya, sekalipun menyerukan pentingnya Negara bagi Islam, tetapi Ahmad Syafii Maarif menolak tesis yang mengatakan bahwa Islam adalah din dan daulah. Sebagaimana telah penulis singgung di atas bahwa, tidak ditemukan landasan yang kuat bahwa Islam adalah din dan daulah, baik didalam Al-Qur'an, Hadits, maupun Piagam Madinah. Apabila Islam merupakan din sekaligus daulah, maka secara otomatis menempatkan posisi agama dan Negara pada posisi sejajar.

Dengan demikian mereka yang meyakini Islam sebagai din sekaligus daulah secara tidak sadar menempatkan alat dengan risalah. Ia menilai tesis yang mengatakan bahwa Islam itu agama sekaligus Negara sebagai kekeliruan serius. Hal ini lantaran agama adalah sesuatu yang immutable (tetap), sementara Negara adalah sesuatu yang mutable (berubah) sesuai dengan tuntutan ruang dan waktu. Dengan menempatkan Negara selevel dengan posisi agama berarti mereka mengagungkan Negara sama halnya dengan mengagungkan agama. ${ }^{7}$ Inilah yang menjadi kekhawatiran Ahmad Syafii Maarif.

Menurut Ahmad Syafii Maarif, posisi Nabi Muhammad dalam Al-Qur'an hanyalah sebagai rasul. Kendatipun tak dapat dipungkiri dalam rekaman historis, ia pernah menjadi pemimpin agama sekaligus pemimpin Negara. Posisinya sebagai rasul Allah tidak pernah berubah sampai ia wafat pada 632 M. kedudukan Nabi Muhammad

\footnotetext{
${ }^{5}$ Ahmad Syafii Maarif, Islam dan Politik, hlm 194

${ }^{6} I b i d .$, hlm 133

${ }^{7}$ Ibid., hlm 195-196
} 
sebatas Rasul Allah termaktub juga dalam Q.S Surat Ali Imran:144. Statement AlQur'an bahwa "Muhammad hanyalah seorang rasul" inilah yang kemudian dijadikan argumentasi Ahmad Syafii Maarif untuk menolak tesis bahwa "Islam adalah agama dan Negara". Bagi Ahmad Syafii Maarif, tesis bahwa "Islam merupakan agama dan negara" mengaburkan hakikat yang sebenarnya dari posisi kenabian Muhammad SAW. ${ }^{8}$

Perspektif Ahmad Syafii Maarif tentang relasi Islam dan Negara di atas pastinya bersebrangan dengan pendapat para pengusung Negara Islam dan formalisasi syariat Islam. Hal ini karena bagi mereka, Islam adalah agama sekaligus Negara. Maka pendiri Negara Islam dan pemberlakuan syariat Islam merupakan perintah tuhan yang wajib dilakukan dan pandang sebagai amal sholeh. Hal ini misalnya dapat dilihat dari pernyataan mantan juru bicara HTI Ismail Yunanto, yang menganggap pendirian Negara Islam sebagai tuntutan akidah Islam. ${ }^{9}$

Menurut Ahmad Syafii Maarif, aspirasi menjadikan Islam sebagai dasar Negara yang dilakukan para tokoh Islam di masa kemerdekaan jika di kaji lebih dalam sesungguhnya tidak jelas aspirasi Islam yang diperjuangkannya. Di matanya, tidak gamblang menempatkan syariat Islam ke dalam mekanisme kehidupan politik modern. Ia mencontohkan Pakistan sebagai Negara Islam yang sampai sekarang masih bingung menempatkan syariat dalam kehidupan kenegaraannya. Dalam konteks ini, ia mengkritik para tokoh Islam masa lampau yang menurutnya lebih mengutamakan wadah, yaitu menegakkan Negara berdasarkan Islam secara formal. ${ }^{10}$

Ketika pertama kali mengikuti kuliah Fazlur Rahman di Chicago, Ahmad Syafii Maarif pernah berkata: "Professor Rahman, please give me one fourt of your knowledge of Islam, I will convert Indonesia into an Islamic state". Namun setelah mengikuti kuiah selama beberapa bulan, kalimat itu tidak pernah lagi di ucapkannya karena sebutan Negara Islam itu tidak diperlukan lagi. Yang terpenting adalah moral Islam harus dijadikan sebagai dasar prilaku bagi masyarakat, jika memang Indonesia ingin menjadi sebuah negeri yang adil dan makmur. Adapun perangkat hukum-hukum Islam, dapat dikawinkan dengan sistem hukum nasional melalui proses demokratisasi. Ia mengacu pada istilah Muhammad Hatta yang berbunyi "janganlah gunakan filsafat

\footnotetext{
${ }^{8}$ Ahmad Syafii Maarif, Islam dan Masalah., hlm 14

${ }^{9}$ Sigit Kamseno, "Komprehisivisme din al-Islam: Kritik atas Konsep Kulturalisme dan Strukturalisme Islam”, Jurnal Politik Islam, Vol. 1 No 2, 2006, hlm 164.

${ }^{10}$ Ahmad Syafii Maarif, Islam di Masa Demokrasi Liberal dan Demokrasi Terpimpin, Prisma No. 5, Tahun XVIII, 1988, hlm 26.
} 
gincu, tampak tetapi tak terasa; pakailah filsafat garam, tak tampak tapi terasa”. Artinya, Negara Indonesia adalah sebuah Negara yang berasaskan pancasila (bukan Islam), akan tetapi nilai-nilai moral Islam harus selalu diketengahkan dalam kehidupan bernegara dan bermasyarakat; meskipun "Negara Islam” tidak tampak, tapi moral Islam tetap dijalankan.

\section{Pemikiran Ahmad Syafii Maarif Islam dalam Bingkai KeIndonesiaan dan Kemanusiaan.}

Dalam karya Ahmad Syafii Maarif ini dengan jelas memperlihatkan dan didukung oleh argumentasi yang dapat dipertanggungjawabkan bahwa antara Islam, ke Indonesiaan, dan kemanusiaan tidak saja berjalan bersama dan seiring, tetapi ketiganya dapat menyatu dan saling mengisi untuk membangun sebuah tatanan yang khas Indonesia. Ketiga kekuatan nilai itu mestilah saling melengkapi.

Agar watak universal Islam tampil dalam wujud kemanusiaan yang adil dan beradab. Sebagai agama yang dipeluk oleh mayoritas penduduk nusantara, semua gerakan yang bercorak Islam harus senantiasa mempertimbangkan dengan cermat dan cerdas atas realitas sosio-historis Indonesia, demi keamanan, kedamain, dan kejayaan agama ini dalam mencapai tujuan mulia yang harus pula ditempuh dengan cara-cara yang mulia dan beradab.

Di luar koridor itu, Islam hanya akan berhenti pada tataran ritual yang kehilangan ruh, sedangkan misi utamanya tercecer di tengah jalan. Bagaimana yang tersisih hanyalah kerangkanya dalam bentuk formal, jika bukan monster, tetapi sepi dari nilai-nilai kemanusiaan yang halus, elok dan sejuk. Ia bukan lagi Islam yang hidup menghidupkan, buka pula Islam kenabian atau Islam Qur'ani yang selalu memberi inspirasi untuk berbuat yang terbaik bagi semua makhluk. ${ }^{11}$

Pesan Ahmad Syafii Maarif yang tersurat dalam buku-bukunya adalah agar para kader menjaga stamina spiritual dan komitmen yang tulus untuk sebuah Indonesia yang adil dan bermartabat. Ia menginginkan terbentuknya sebuah Indonesia sebagai perumahan, yang membuat betah bagi kehidupan bersama sebagai bangsa dan Negara. ${ }^{12}$

\footnotetext{
${ }^{11}$ Muhammad Iqbal, The Recontruction of Religion Thought In Islam. (Lahore, Kashmiri Bazar, 1971), hlm. 148

${ }^{12}$ Jakob Oetama, Berpikir Ulang Tentang Keindonesiaan, (Jakarta: Penerbit Buku Kompas, 2011), hlm 4 .
} 
Kelalaian kita sejak proklamasi adalah sikap yang tidak serius dalam upaya memelihara dan menjaga sesuatu yang tidak given ini, karena menyangka semuanya sudah beres, semuanya sudah tertetap. Pandangan serba parochial inilah yang menjadi salah satu sebab mengapa bangsa ini sering dihadapkan kepada letupan-letupan sosial politik yang menguras energi dan perhatian, tidak jarang pula berdarah-darah.

Peradaban Islam tidak boleh dibiarkan seperti kerakap diatas batu, mati tidak, hidup pun enggan. Harus ada keberanian untuk melakukan keberanian untuk melakukan terobosan dengan berpijak atas dalil-dalil agama yang dipahami secara benar dan cerdas, tekstual sekaligus kontekstual. Penafsiran Islam klasik jangan dijadikan berhala, sehingga hilang keberanian untuk menafsirkan Islam dengan cara baru, segar, dan bertanggung jawab. Tafsiran baru ini harus benar dalam perspektif ilmu, tetapi tetap berada dalam parameter iman yang tulus.

Kemudian untuk semua gerakan Islam di Indonesia, yang harus diingat selalu dan diperhitungkan dengan hati-hati adalah agar benturan-benturan yang berbau agama, etnis dan kultural tidak boleh terjadi lagi di masa yang akan datang. Ongkosnya terlalu mahal yang harus dibayar, dan sampai batas-batas tertentu telah merusak suasana tatanan nusantara yang elok itu. Indonesia sebagai bangsa dan Negara yang belum berusia satu abad, dengan pengalaman manis dan pahit yang telah dilaluinya, harus pandai belajar secerdas mungkin dan memetik kearif lokal dari kemampuan penuh roda dan pengalaman yang sangat berharga itu. ${ }^{13}$

Karena kita telah memilih demokrasi sebagai sistem politik politik yang sudah diperjuangkan sejak awal pergerakan nasional pada abad yang lalu, maka konsistensi kita dalam membelanya tidak boleh kepalang tanggung, sekalipun sering sangat melelahkan. Sebagaimana telah disinggung sebelumnya, demokrasi ditangan para petualang politik bisa menjadi sumber malapetaka dan kesengsaraan, seperti jelas terlihat dalam politik luar negeri Amerika yang imprealistik di bawah Presiden Bush (2001-2009) yang menghancurkan bangsa-bangsa lain dengan berbagai dalih palsu.

Manusia tidak beriman pun harus dilindungi oleh Negara selama mereka patuh kepada konstitusi dan hukum positif yang berlaku di Indonesia, ketentuan serupa juga berlaku bagi mereka yang mengaku beriman, selama dia tidak melanggar undangundang. Beriman atau tidak beriman adalah pilihan bebas seseorang, asal semuanya itu

\footnotetext{
${ }^{13}$ Ahmad Syafii Maarif, Islam dalam Bingkai Keindonesiaan dan Kemanusiaan: Sebuah Refleksi Sejarah, hlm 450.
} 
dilakukan dengan jujur dan penuh tanggung jawab serta tidak eksklusif. Dalam perspektif ini, seseorang yang berpindah agama ke agama lain atau memilih tidak beragama merupakan hak asasi manusia yang wajib di hormati. Fikih klasik Islam yang mengukum mati orang murtad harus di tinjau kembali karena berlawanan dengan ruh Al-Qur'an, sekalipun Allah marah kepada mereka yang berganti iman.

Al-Qur'an haruslah dipahami secara holistik, diikuti benang merah ajarannya, sehingga di depan mata kita terlihat jelas bentangan sebuah pandangan dunia yang elok, asri dan diliputi rasa keadilan yang penuh rahmat untuk semua makhluk, tanpa terkecuali. Barangkali dunia ideal semacam ini tidak mungkin diraih dimuka bumi, tetapi roda peradaban harus bergerak kearah itu tanpa merasa letih, sekalipun perjalanan dipenuhi onak dan duri. Apa yang dinamakan perjuangan hidup adalah menyingkirkan onak dan duri itu dengan sikap berani yang penuh kearifan. Manakala umat Islam mampu menampilkan roda kehidupan yang sarat dengan nilai-nilai kemanusian, itulah hakikat dakwah yang menghidupkan dakwah yang sejati. ${ }^{14}$

Menciptakan sebuah bangunan Islam dalam bingkai keIndonesiaan dan kemanusiaan dalam suatu tarikan nafas lebih merupakan kerja dakwah dan kebudayaan bukan sekedar kerja politik. Melalui pendekatan dakwah dan kebudayaan, nilai-nilai dasar Islam, ke Indonesiaan dan kemanusiaan dapat dirancang dengan lebih teliti, sabar dan berdaya jangka jauh. Jika nilai-nilai dasar ini sudah menguat, maka pengaruhnya di ranah politik juga akan terasa, yaitu tampilnya politik berkeadaban, bukan politik kekerasan yang kerjanya menyikut kiri-kanan, tidak peduli orang lain tersingkir dan tersungkur. Politik yang dibimbing oleh nilai-nilai profetik pastilah akan bermuara pada kedamaian dan keadilan, sekalipun para pelakunya berbeda ideologi.

Ditangan para pemimpin dengan kualitas diatas, persenyawaan antara Islam yang di dukung oleh agama-agama lain yang hidup di tanah air kita, dengan keIndonesiaan dan kemanusian, bangsa ini akan menemukan jati dirinya yang sejati dan padu. Dengan pensenyawaan ini, pancasila akan diberi fondasi spitual kenabian yang tahan banting. Sebuah Indonesia masa depan yang utuh sungguh memerlukan dasar spiritual kultural yang kukuh dalam upaya menopang harkat martabat bangsa ini untuk masa yang panjang, tanpa batas.

\footnotetext{
${ }^{14}$ Ahmad Syafii Maarif, Islam: Kekuatan Doktrin dan Keagamaan Umat, hlm 60-62.
} 


\section{Toleransi Beragama Ahmad Syafii Maarif}

Toleransi beragama dalam gagasan Ahmad Syafii Maarif, menekankan agar setiap pemeluk agama untuk tidak selalu mengklaim kebenaran untuk dirinya sendiri serta mendiskreditkan pemeluk agama yang lain, tetapi dalam pandangannya hendaklah setiap pemeluk agama memberikan kebebasan kepada pemeluk agama lain untuk memeluk apa yang mereka yakini benar, serta tidak menuduh pemeluk agama lain salah, karena dengan saling tuduh dan mengucilkan pemeluk agama yang berbeda dari yang diyakininya akan dapat menimbulkan sebuah perpecahan sehingga tidak akan pernah ada peradaban baru yang dapat di torehkan oleh bangsa Indonesia yang dikenal dengan kebesaran jiwa dan toleransinya. ${ }^{15}$

Demikian juga sebaliknya, toleransi antar umat beragama adalah cara agar kebebasan beragama dapat terlindungi dengan baik. Kebebasan dan toleransi tidak dapat diabaikan. Namun yang sering kali terjadi adalah penekanan dari salah satunya, misalnya penekanan kebebasan yang mengabaikan toleransi dan usaha untuk merukunkan dengan memaksakan toleransi dengan membelenggu kebebasan. Untuk dapat mempersandingkan keduanya, pemahaman yang benar mengenai kebebasan beragama dan toleransi antar umat beragama merupakan sesuatu yang penting dalam kehidupan sehari-hari dalam bermasyarakat.

\section{KESIMPULAN}

Pemikiran Ahmad Syafii Maarif tentang Islam dalam bingkai ke Indonesiaan dan kemanusiaan adalah suatu pemikiran integratif antara Islam, keIndonesiaan dan kemanusiaan dimana ketiga hal tersebut dapat saling berintegrasi satu sama lain untuk mewujudkan peradaban Islam di Indonesia yang maju, progresif, ramah terbuka dan inklusif. Pemikiran ini memiliki visi untuk memberikan ruang agama Islam agar pemikiran mengenai Islam, keIndonesiaan dan kemanusiaan dapat diterima dan tidak perlu diperdebatkan lagi sehingga Islam dapat berjalan sejalan dengan ketiga hal tersebut sehingga bermanifestasi menjadi sebuah Islam yang memayungi dan memberi rasa keadilan, keamanan dan perlindungan bagi seluruh rakyat Indonesia.

\footnotetext{
${ }^{15}$ Ahmad Syafii Maarif, Islam dan Politik: Teori Belah Bambu Masa Demokrasi Terpimpin 1959-1965, hlm 193.
} 


\section{DAFTAR PUSTAKA}

Iqbal, Muhammad. 1997. The Recontruction of Religion Thought In Islam. Lahore, Kashmiri Bazar, 1971.

Kamseno, Sigit. 2006. “Komprehisivisme din al-Islam: Kritik atas Konsep Kulturalisme dan Strukturalisme Islam”, Jurnal Politik Islam, Vol. 1 No 2.

Maarif, Ahmad. Syafii, 1985. Islam dan Masalah Kenegaraan: Studi tentang Percaturan dalam Konstituante, Jakarta: LP3ES.

Maarif, Ahmad. Syafii, 1996. Islam dan Politik: Teori Belah Bambu Masa Demokrasi Terpimpin 1959-1965, Jakarta: Gema Insani Press.

Maarif, Ahmad. Syafii, 1997. Islam: Kekuatan Doktrin dan Keagamaan Umat, Yogyakarta: Pustaka Pelajar.

Maarif, Ahmad. Syafii, 1998. Islam di Masa Demokrasi Liberal dan Demokrasi Terpimpin, Prisma No. 5, Tahun XVIII.

Maarif, Ahmad. Syafii, Islam dalam Bingkai KeIndonesiaan dan Kemanusiaan: Sebuah Refleksi Sejarah Bandung: Mizan Pustaka.

Oetama, Jakob. 2011. Berpikir Ulang Tentang KeIndonesiaan, Jakarta: Penerbit Buku Kompas. 